\title{
Evaporation flow assessment from petroleum product storage tanks exposed to fire conditions
}

\author{
S. Ginestet ${ }^{1, *}$ and C. Le Bot ${ }^{2}$ \\ ${ }^{1}$ LMDC, Université de Toulouse, INSA, UPS, 135 av. de Rangueil, 31077 Toulouse, France \\ ${ }^{2}$ Institut National Polytechnique de Bordeaux, I2M UMR 5295, 33400 Talence, France
}

Received: 15 January 2018 / Accepted: 14 June 2018

\begin{abstract}
Fire around storage tanks for petroleum products can have disastrous consequences for the environment and the population. These fires, due to accident or arson, are very well managed by security divisions but, nevertheless, involve the release of an amount of vapour from the petroleum present in the storage device. The exposure of a non-refrigerated aboveground liquid petroleum or petroleum product storage tank to fire can also lead to internal overpressure. PV-valves ensure that the normal and emergency venting requirements are satisfied, and determination of such requirements is key for the safety of petroleum tanks and should not be underestimated. This paper presents and discusses some methods that can be used to evaluate the vapour flow. In the aim of finding an exact answer rapidly, a thermal analytical approach is first investigated, which reveals the complexity of the solution. Thus, a numerical approach, based on finite-volume description, is used to set the first steps of the flow assessment. Based on a thermodynamic hypothesis, a simplified method is finally put forward for the evaluation of the amount of vapour released. The algorithm used to determine how temperature, pressure and flow evolve over time, which is very useful information for the safety of these devices, is then detailed and the results discussed.
\end{abstract}

\section{Nomenclature}

$C p_{1} \quad$ Liquid specific heat $(\mathrm{J} / \mathrm{kg} \mathrm{K})$

$C p_{\mathrm{v}} \quad$ Vapour specific heat $(\mathrm{J} / \mathrm{kg} \mathrm{K})$

$v_{\text {liq }} \quad$ Liquid specific volume (constant) $\left(\mathrm{m}^{3} / \mathrm{kg}\right)$

$T_{0} \quad$ Initial temperature $\left({ }^{\circ} \mathrm{C}\right)$

Lv Vaporisation enthalpy $(\mathrm{kJ} / \mathrm{mol})$

$T_{\mathrm{r}} \quad$ Reduced temperature $\left(T / T_{\mathrm{c}}\right)$

$T_{\mathrm{c}} \quad$ Critical temperature

$T_{\infty} \quad$ Air temperature around the storage tank $\left({ }^{\circ} \mathrm{C}\right)$

$\varphi \quad$ Heating flux $\left(\mathrm{W} / \mathrm{m}^{2}\right)$

$k$ Equivalent thermal conductivity $(\mathrm{W} /(\mathrm{m} \mathrm{K}))$

$x \quad$ Quality (\%) $x=m_{\mathrm{v}} / m_{\text {to }}$

$r \quad$ Radius $(\mathrm{m})$

$R \quad$ Radius of storage tank (m)

$H \quad$ Height of storage tank (m)

$z \quad$ Height $(\mathrm{m})$

$h$ Convective heat transfer coefficient $\left(\mathrm{W} /\left(\mathrm{m}^{2} \mathrm{~K}\right)\right)$

$t \quad$ Time (s)

Sc Heat source $\left(\mathrm{W} / \mathrm{m}^{3}\right)$

\footnotetext{
* Corresponding author:

stephane.ginestet@insa-toulouse.fr
}

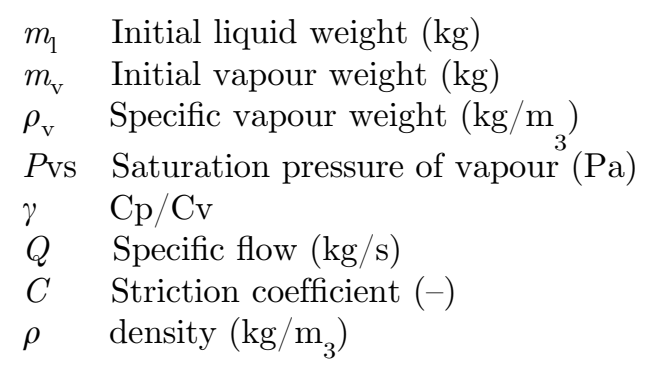

\section{Acronyms}

API American Petroleum Institute

ASME American Society of Mechanical Engineers

LNG Liquefied Natural Gas

\section{Introduction}

Storage tanks in refineries and chemical plants contain large volumes of flammable chemicals. A small accident may lead to million-dollar property loss and a few days of production 
interruption (Chang and Lin, 2006). Fire and explosion account for $85 \%$ of the storage tank accidents. In a petroleum storage tank, outbreathing results from the vapour expansion and liquid vaporization occurring when a tank absorbs heat from an external fire. All storage tanks are equipped with devices allowing the vapour to escape. The pressure relief device or emergency venting system must be suitable to relieve the flow capacity required for the largest single contingency or any reasonable and probable combination of incidents. This parameter, the treatment of discharges, is identified as an active method in the design phase by Prugh (1992) and as a relevant protection measure by experts Argyropoulos et al. (2012), Wang et al. (2013). The venting requirements provided in the API standard (API, 1998) are based on studies of hexane stored in steel tanks. Sound engineering judgement should be applied to extrapolate these results to other liquids and non-metallic tanks. Detailed engineering studies of a particular tank and its operating conditions may indicate that the appropriate venting capacity for the tank is not the one estimated in accordance with this standard. If the tank's operating conditions could deviate from those used to develop the standard, detailed engineering studies should be performed. Many standards or recommendations can be helpful for the design of equipment (API, 2002, 2008, 2009a, 2009b; CSTB, 2002; ASME, 2009). Engineering studies used to determine technical parameters (cross-section, length, etc.) of these devices can lead to tedious calculations with broad hypotheses. For such phenomena as BLEVE (case of liquid propane flows through pipe at high pressure and in low temperature conditions), a risk assessment methodology by using fuzzy logic is proposed in Karimpour et al. (2016). The fire duration is also an important parameter, studied in Hauser et al. (2001), who give guidelines to help the designers for three special external fire cases. The aim of this paper is to present and discuss some methods that can be used to evaluate the vapour flow. To obtain a quick, exact answer, a thermal analytical approach is first investigated and shows the complexity of the solution. A numerical approach, based on finite-volume description, is then adopted in order to set the first steps of the flow assessment. Based on thermodynamic hypotheses, a simplified method is finally proposed, allowing an evaluation to be made of the amount of vapour released. The calculation algorithm used to determine the information indispensable for the safety of these devices: evolution of temperature, pressure and flow over time, is detailed and discussed. The main aim of this communication is to present a simplified approach for the evaluation of vapour flows.

\section{Hypotheses - methodology}

The study concerns a cylindrical petroleum storage tank exposed to fire. The heat emitted by the fire warms the whole lateral side of the tank by radiation. The petroleum is also heated by conduction and convection, causing the liquid phase to evaporate. The study reports on the determination of the dynamic thermal behaviour of the hydrocarbon contents according to some hypothesis.

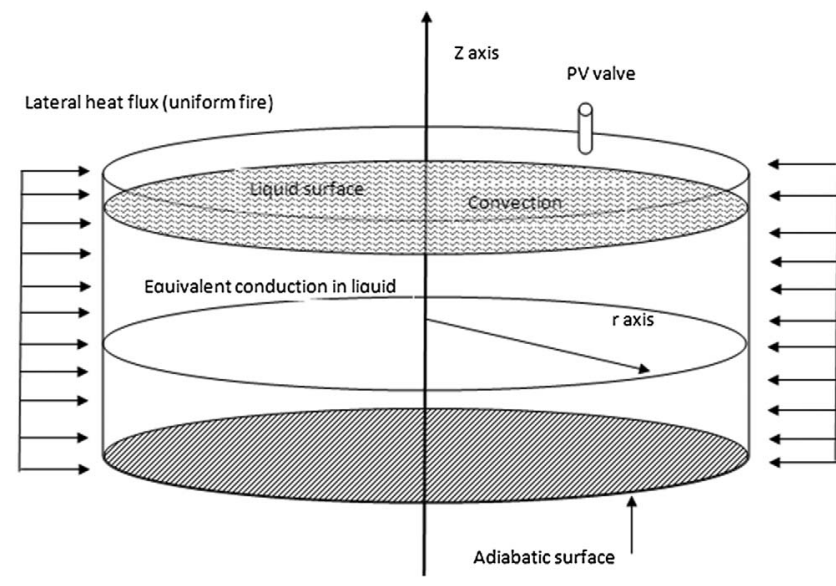

Fig. 1. Overview of the case under study.

Many parameters are difficult to master so various hypotheses are proposed to develop an analytic solution close to real conditions. First, the heat flux from the fire is uniformly distributed on the side of the tank and its value varies from 20 to $40 \mathrm{~kW} / \mathrm{m}^{2}$ (CSTB, 2002). Note that the radiant energy flux from large open hydrocarbon fires can be sufficiently high to threaten the structural integrity of neighbouring storage tanks. This case is not considered in our study. Adequate fire protection to guard against the catastrophic failure of storage vessels is studied in Nitesh and Gupta (2007) which deals with the use of a water-spray system to protect an adjoining tank from a tank on fire. So in Nitesh and Gupta (2007) the amount of radiative heat flux falling on the adjoining tank is first calculated and is then used to determine the amount of water required to prevent any serious temperature rise in the adjoining tank. The present work focuses on overpressure inside the tank.

In contact with the soil, the tank base is adiabatic and the tank top is considered to be in contact with the atmosphere. The heat convection in the liquid phase is modelled with an equivalent thermal conduction coefficient. The height of the liquid phase is fixed at the beginning of the process and the initial temperature is $20^{\circ} \mathrm{C}$. Thermal transfers are axisymmetric and therefore cylindrical coordinates will be used (Fig. 1).

The internal source term $S$ corresponds to a phase change. This leads to the following equations:

Heat balance in the fluid (unsteady two-dimensional conduction)

$$
\begin{aligned}
& \rho C_{p} \frac{\partial T(r, z, t)}{\partial t}= \\
& \quad k \times\left(\frac{\partial^{2} T(r, z, t)}{\partial r^{2}}+\frac{1}{r} \frac{\partial T(r, z, t)}{\partial r}+\frac{\partial^{2} T(r, z, t)}{\partial z^{2}}\right)+S .
\end{aligned}
$$

Boundary conditions

- Adiabatic base of the storage tank

$$
-k \times\left(\frac{\partial T(r, 0, t)}{\partial z}\right)=0 .
$$


- Heat convection at the top of the storage tank

$$
-k \times\left(\frac{\partial T(r, H, t)}{\partial z}\right)=h \times\left(T(r, H, t)-T_{\infty}\right) .
$$

- Fire around the storage tank

$$
-k \times\left(\frac{\partial T(R, z, t)}{\partial r}\right)=\varphi_{0} .
$$

Initial condition:

$$
T(r, z, 0)=20{ }^{\circ} \mathrm{C} .
$$

$$
\text { Axis of symmetry: }-k \times\left(\frac{\partial T(0, z, t)}{\partial r}\right)=0 \text {. }
$$

These equations are based on the unsteady form of the heat equation, which combines the other relevant heat transfer mechanisms discussed above as well as the phase change that will occur within the liquid portion of the tank. The phase change is considered in our simplified modelling but it was decided here not to consider or account for the effects of the static head of liquid hydrocarbon on the increase in saturation temperature of the liquid hydrocarbon here.

Because an open system is analysed here, the mass balance is included in the description of our problem. For example, the boiling of the liquid close to the wall may start a mixing process. This process is discussed using an equivalent thermal conductivity.

The "fire exposure" conditions are as follows: the tank is fully engulfed in flames; the fire radiates to the lateral wall only; as the fire radiates to the whole vertical wall of the tank, the conditions that thermally characterize the heat load to the tank are those available in the literature (CSTB, 2002) (long-wave emissivity of the fire, long-wave absorptivity of the tank wall, temperature of the fire source, etc.).

Specifically, the convection conditions inside the tank (both in the vapour space and in the liquid space) are taken into account. The assumed convection flux on the tank outside wall is considered negligible relative to the radiation flux, even if it is probable that the dry bulb temperature of the air thermally communicating with the tank will be significantly higher than the ambient temperature due to the presence of the fire.

\section{An approach to the analytical solution}

An exhaustive study of the literature was conducted to reach a classic analytical solution. One of the most complete documents on conduction problems (Ribaud, 1960) does not handle this particular case. Indeed, the most complete solution available in the literature on cylindrical problems does not take lateral heat flux into account. Even so, the analytical solution is very cumbersome to use. Other references investigated (Carlsaw and Jeager, 1959; Ingersoll et al., 1955) are rather old; they remain too general and present only scholar solutions.

The paper that gives the closest solution to the problem under study can be found in De Vriendt (1990). Chapter 11 "Non-stationary conduction with several dimensions" describes many configurations (wall, cylinder) and boundary conditions (Neumann, Dirichlet and Fourier). The case of a short cylinder is solved thanks to the "separation principle", as the sum of an infinite rectangular wall and an infinite cylinder. The analysis of the proposed solutions makes reference to many Bessel functions and leads to the tedious use of numerous Bessel coefficients.

Finally, the solving method considered uses the thermal quadrupole method (Maillet et al., 2000). It implies solving two sub-systems: a short cylinder with zero lateral flux and fixed upper and lower flux, and a short cylinder with nonzero lateral flux and zero upper and lower flux. The solving has to be done in Laplace space and again leads to the tedious use of Bessel functions.

To conclude, it can be said that, in this case, an analytical solution is very difficult to achieve since these equations are complex to solve directly.

This search of the literature encouraged us to investigate a numerical solution. In our study, the system was solved using the finite volume technique in Matlab ${ }^{\circledR}$. The results in conduction, the heat balances, are correct, but the liquid vaporization is very difficult to consider with the effects of the various specific weights. The first results showed consistency in the solution obtained during the heating of the hydrocarbon with the lower heat flow density of $20 \mathrm{~kW} / \mathrm{m}^{2}$ (Fig. 2).

To conclude on this part, it appears relevant to investigate a form of simplified modelling, since using a numerical method or analytical solution to solve the equations will be long and require a lot of work. However, the accuracy of the numerical method and analytical solution must be more precise, on condition that the calculations could be entirely led with correct hypothesis.

\section{Simplified modelling}

In the API standard (API, 1998), the vapour venting requirements are based on studies using hexane. For the present study, hexane is also considered as a representative substance, the physical properties of which were issued drawn from Carruth and Kobayashi (1973), Cengel and Boles (2001), Guo et al. (2001), Handbook of Chemistry (2004), Majer and Svoboda (1985a, 1985b), NIST (2012), Williamham et al. (1945).

\subsection{Thermal modelling}

The case presented is a vertical closed cylinder (height $h$, radius $R$, volume $V$ ) subjected to a lateral radiative heat flux $\varphi$. The first hypothesis is that the system has a uniform temperature during the heating phase (high conductivity). This is not valid if only conduction is considered. A quick study based on thermal diffusivity (about $10^{-7} \mathrm{~m}^{2} / \mathrm{s}$ ) shows that the liquid thermal properties vary greatly (Kourneta 

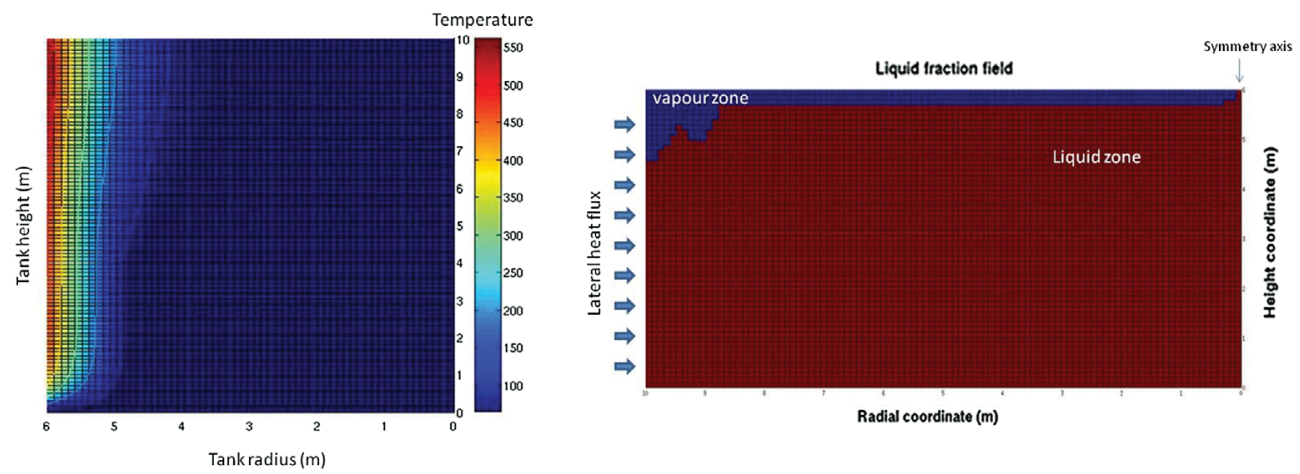

Fig. 2. Overview of numerical results (left temperature field, right quality field).

et al., 1994) and a convection phenomenon appears quickly. Therefore, it is legitimate to consider a higher equivalent conductivity. A similar approach was used by (de Nevers, 1997). In this study, the heating of propane and other liquid-filled tanks by the ambient air and surroundings and by a radiative source is investigated. Lumped-parameter heat transfer models describe correctly the experimental tests of this behaviour. In more complex situations, these models give only intuitive guidance but not detailed predictions.

\subsection{Thermodynamic modelling}

The liquid vaporization leads us to take the vaporization enthalpy into consideration, as a function of temperature (NIST, 2012)

$$
L v(T)=A \times \exp \left[\left(-\alpha \times \frac{T}{T_{\mathrm{c}}}\right) \times\left(1-\frac{T}{T_{\mathrm{c}}}\right)^{\beta}\right] .
$$

With, for hexane,

$$
\begin{aligned}
& A(\mathrm{~kJ} / \mathrm{mol})=43.85, \\
& \alpha=-0.039, \\
& \beta=0.397, \\
& T_{\mathrm{c}}(\mathrm{K})=507.4, \\
& T, \text { temperature. }
\end{aligned}
$$

Other data regarding state equation of other fluids are available in Neau et al. (1995) and more recently in de Hemptinne and Béhar (2006). A more precise description of these phenomena can be found in Lacassagne et al. (2017) who explained the physical phenomena acting in the liquid phase during the transfer of a gas at a flat twophase interface and who measured the influence of these phenomena on mass exchanges.

As the system is closed, the vaporization leads to a vapour pressure rise at the top of the cylinder. This vapour pressure is equal to the sum of the saturated vapour pressure and the atmospheric pressure. Initially, the tank contains liquid and vapour at equilibrium $\left(20^{\circ} \mathrm{C}\right)$.
The initial specific volume is fixed, which allows the initial quality $(x)$ and initial weights (vapour $m_{\mathrm{v}}$ and liquid $m_{\mathrm{l}}$ ) to be calculated. The whole weight is $m_{\text {tot }}$. The initial enthalpy is calculated in (5), and the reference for enthalpy is $H=0 \mathrm{~J}$ for liquid at $0{ }^{\circ} \mathrm{C}$.

$$
H_{0}=m_{1} \times C p_{1} \times T_{0}+m_{\mathrm{v}} \cdot\left(C p_{\mathrm{v}} \times T_{0}+L v\left(T_{0}\right)\right) .
$$

During the time interval $\mathrm{d} t$, enthalpy variation is directly linked to the energy carried by $\Phi$ (incoming heating flux from lateral fire):

$$
\frac{\mathrm{d} H}{\mathrm{~d} t}=\Phi
$$

So the enthalpy becomes

$$
H_{1}=H_{0}+\Phi \times \mathrm{d} t .
$$

This new value permits the new temperature $T_{1}$ to be calculated, taking the following two criteria into account.

\subsection{Convergence criteria}

Criterion \# 1

$\mathrm{T}_{1}$ should verify he value $H_{1}$. The quality $(x)$ and the specific liquid and vapour enthalpies corresponding to $H_{1}$ can be identified using $L v$. An infinity of $(T, P)$ fit this criterion.

Criterion \# 2

The saturation pressure of vapour $P_{\mathrm{vs}}$, is calculated using Antoine's law expressed in (9)

$$
\log \left(P_{\mathrm{vs}}\right)=A-\frac{B}{T+C}
$$

with (Majer and Svoboda, 1985a; Persson et al., 2003)

$$
\begin{aligned}
& A=4.00266, \\
& B=1171.53 \mathrm{~K}^{-1}, \\
& C=-48.784 \mathrm{~K} .
\end{aligned}
$$

The vapour specific volume, obtained through Avogadro's law, and the quality give the vapour specific volume 


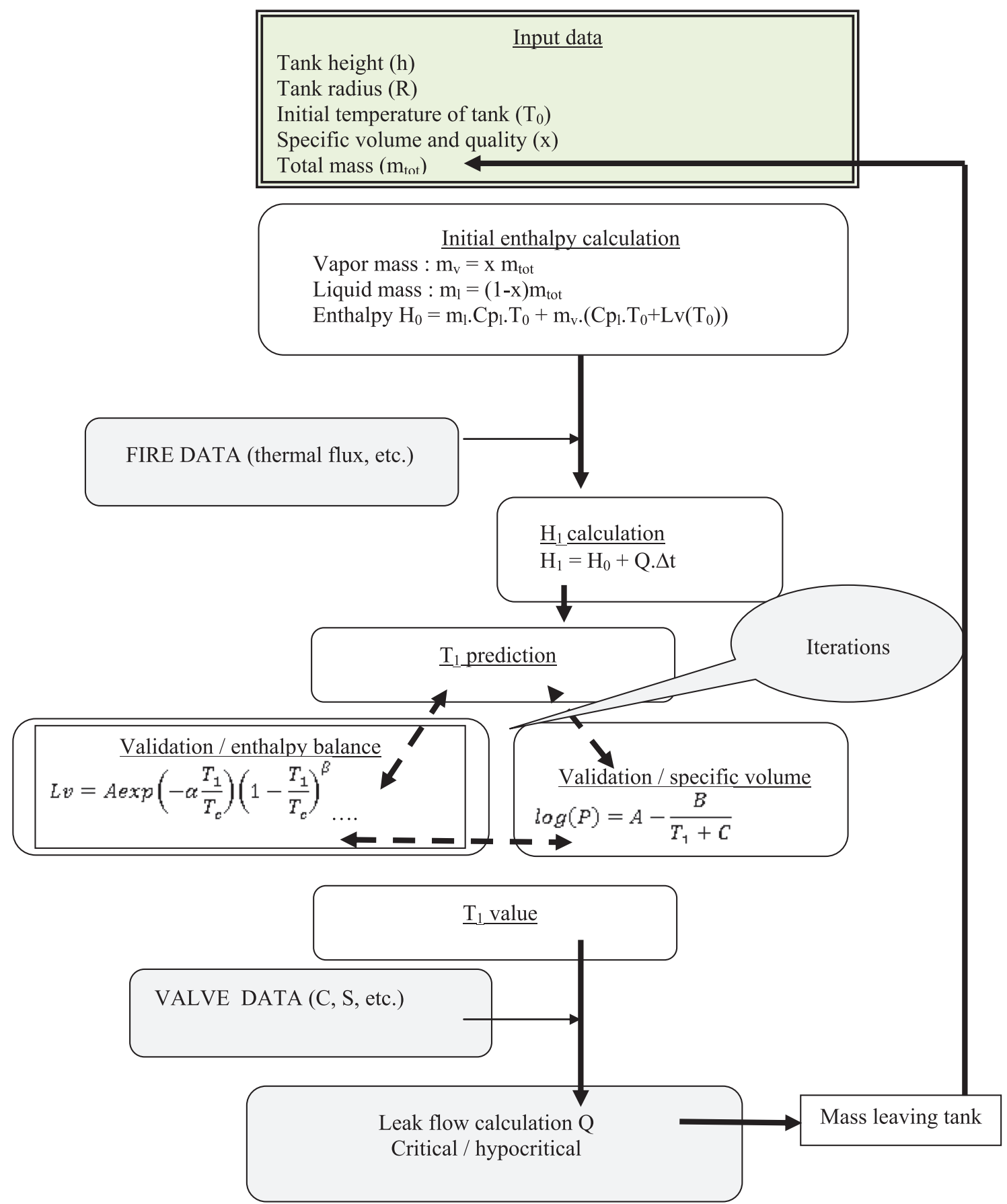

Fig. 3. Algorithm used to evaluate the leak flow value.

in the tank. The two values are compared and iteration leads to the appropriate specific volume for the vapour. The objective is to find both the enthalpy and vapour specific volume corresponding to the value $T_{1}$.

The vapour flow through the valve is then calculated with a classic fluid dynamics relation. The emptying of the tank is then computed step by step (Fig. 3).

The critical state of the flow is determined using $P_{n+1} /$ $P_{n}(10,11)$ between step $n$ and step $n+1$.
- Critical state:

$$
\frac{P_{n+1}}{P_{n}} \leq\left(\frac{2}{\gamma+1}\right)^{\frac{\gamma}{\gamma-1}}
$$

- Hypocritical state:

$$
\frac{P_{n+1}}{P_{n}}>\left(\frac{2}{\gamma+1}\right)^{\frac{\gamma}{\gamma-1}}
$$




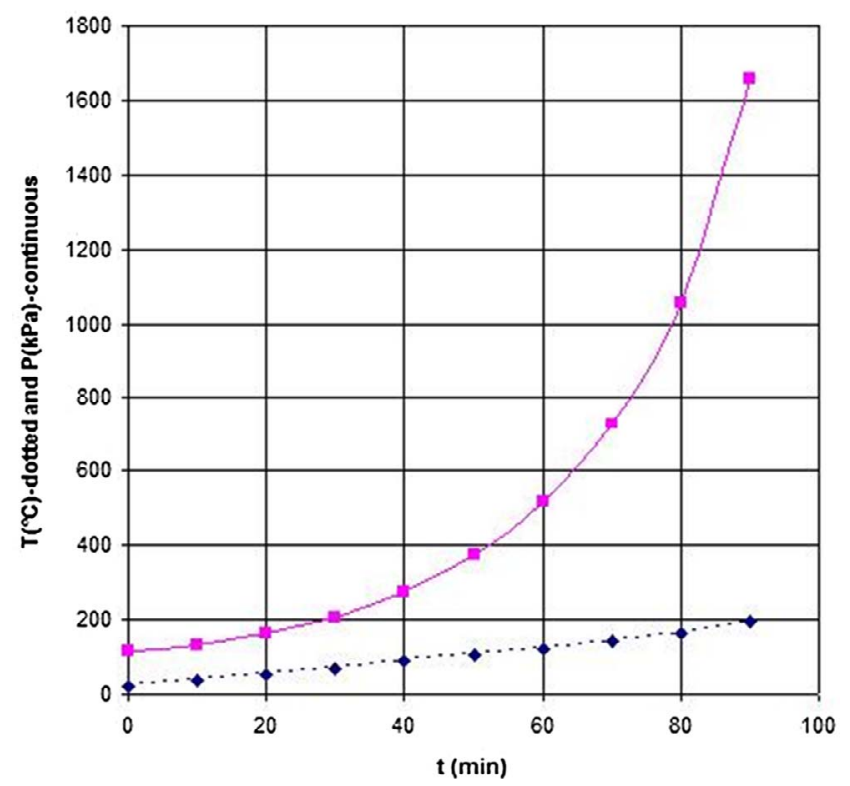

Fig. 4. Internal temperature and pressure evolution of hexane in the storage tank.

This leads to the calculation of the mass vapour flow $Q$

- Critical state:

$$
Q=C S \sqrt{\gamma \times P_{n} \times \rho_{n}} \sqrt{\left(\frac{2}{\gamma+1}\right)^{\frac{\gamma+1}{\gamma-1}}} .
$$

- Hypocritical state:

$$
\begin{aligned}
Q= & C S \sqrt{2 \times\left(\frac{P_{n+1}}{P_{n}}\right)^{\frac{2}{\gamma}} P_{n} \times \rho_{n} \times \sqrt{\left(\frac{\gamma}{\gamma-1}\right)}} \\
& \times \sqrt{1-\left[\left(\frac{P_{n+1}}{P_{n}}\right)^{\frac{\gamma-1}{\gamma}}\right]} .
\end{aligned}
$$

\section{Results and discussion}

The calculations presented in the previous part were applied to a cylindrical tank $(R=6 \mathrm{~m}, h=20 \mathrm{~m})$ exposed to a classic fire $\left(20 \mathrm{~kW} / \mathrm{m}^{2}\right)$. The initial temperature of the system (hexane) was taken to be $20^{\circ} \mathrm{C}$. The tank was equipped with one $\mathrm{PV}$ valve $5 \mathrm{~cm}$ in diameter.

In Figure 4, the temperature increases quite linearly, due to the equivalent conduction hypothesis and constant lateral heat flux. The simplified modelling gives the expected behaviour of the mean fluid temperature. On the

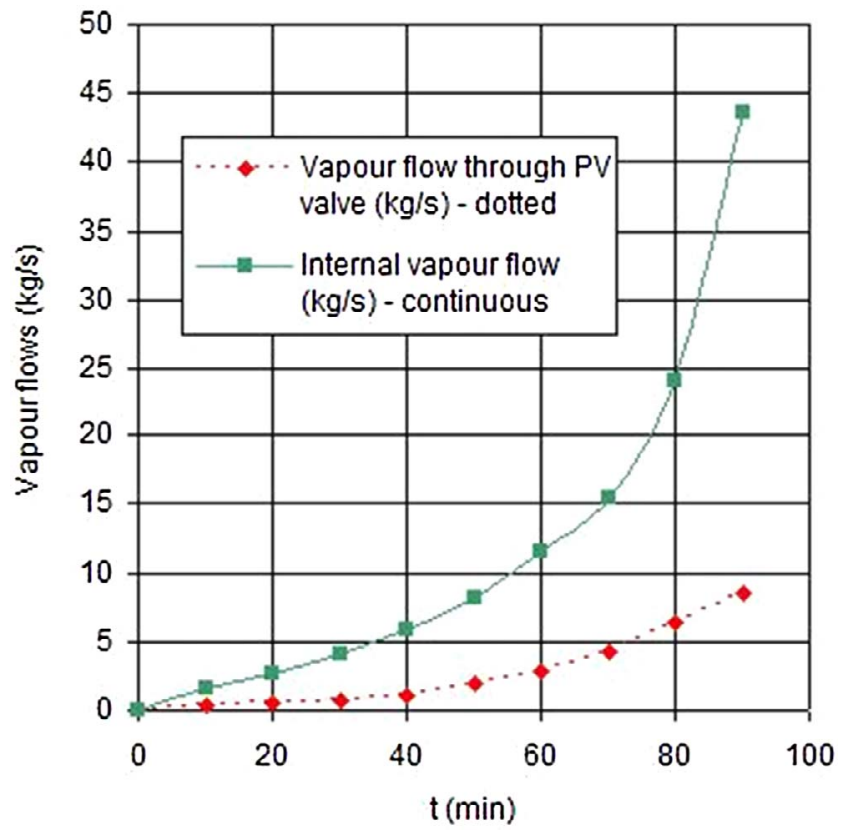

Fig. 5. Internal hexane vapour flow and vapour flow through the PV valve of the storage tank.

other hand, the internal mean pressure rises exponentially, due to Clapeyron's law and the rising temperature.

In this case study and in these conditions, we can observe that the internal vapour generation rate is higher than the vapour flow through the PV valve (Fig. 5). These results are in accordance with the pressure elevation observed in Figure 4. In this case, the external fire must be extinguished to interrupt the increase of internal pressure. It can also be considered that the PV valve diameter is not suited to these tank characteristics (height, radius, etc.).

The methodology developed in this study assesses this kind of parameter fairly easily without requiring significant calculation time. Many cases can be investigated using this approach. First, several PV valve diameters can be tested to determine the effects on the internal pressure in the tank in order to see whether the envelope is suitably designed in terms of shear stress and material behaviour. Then, the effect of various heating fire flows (intensity, part of the envelope exposed) can also be considered. However, the model developed in this study can be completed by considering other liquids (petroleum mixtures) and other boundary conditions (especially for the upper face of the storage tank).

\section{Conclusion}

Knowledge of the thermal behaviour of the petroleum storage tanks is needed to evaluate vapour flows. This data cannot be easily determined by an analytical approach, even if the case study seems to be a conventional one. On the other hand, numerical simulation can lead to very long, difficult calculations, especially because of the phase change. The 
method presented here enables the thermodynamic properties $(T, P)$ of the fluid to be investigated quite easily, assuming simplified modelling. Then a technical approach is used to evaluate the flow to be evacuated by venting devices. These results can be compared with the recommendations presented in API (1998). The behaviour of other storage tanks exposed to fire, such as LPG tanks, has already been investigated (Aydemir et al., 1988; Chen and Lin, 2001; Landucci et al., 2009a). However a simplified approach such as the one presented in this paper could also be applied to these systems in order to provide a new way of evaluating vapour flows in these particular two-phase losses. The final objectives in Landucci et al. (2009a) are to evaluate the quantitative assessment of the risk inherent in escalation scenarios triggered by fire. Other simplified models for estimating the vessel time to failure (ttf) with respect to the radiation intensity on the vessel shell were obtained in Landucci et al. (2009b) by means of a multi-level approach to the analysis of vessel wall failure under different fire conditions. The behaviour of the structure of storage tanks must also investigated. For instance, in Subba and Gorla (2010), an LNG storage tank was simulated computationally and evaluated probabilistically in view of the several uncertainties in the fluid, structural, material and thermal variables governing the LNG tank. Finally the results of our study could be integrated in computer-automated tools used for quantitative risk assessment in a typical petroleum industry, such as Khan and Abbasi (2000). In case of fire, engineering models have been developed to predict foam spread and extinguishment under fire conditions on liquid fuels in some other research projects (Persson et al., 2003).

\section{References}

API (1998) Venting atmospheric and low-pressure storage tanks (nonrefrigerated and refrigerated), API Standard 2000, 5th edn., API, Washington, DC.

API (2002) Design and construction of large, welded, lowpressure storage tanks. API Std 620, API, Washington, DC.

API (2008) Sizing, selection, and installation of pressurerelieving devices in refineries, Part I sizing and selection, API, RP 520, API, Washington, DC.

API (2009a) Guide for pressure-relieving and depressuring systems, API, RP 521API, Washington, DC.

API (2009b) Inspection of pressure-relieving devices, API, RP 576, API, Washington, DC.

Argyropoulos C., Christolis M., Nivolianitou Z., Markatos N. (2012) A hazards assessment methodology for large liquid hydrocarbon fuel tanks, J. Loss Prev. Process Ind. 25, 329 335.

ASME (2009) Pressure relief devices boiler $\&$ pressure vessel code, section VIII, division 1, rules for construction of pressure vessels, ASME, PTC 25.

Aydemir N.U., Magapu V.K., Sousa A.C.M., Venart J.E.S. (1988) Thermal response analysis of LPG tanks exposed to fire, J. Hazard. Mater. 20, 239-262.

Carlsaw H.S., Jeager J.C. (1959) Conduction of heat in solids, Oxford University Press, Oxford, UK, 959 p., ISBN01985336831 .
Carruth G.F., Kobayashi R. (1973) Vapor pressure of normal paraffins ethane through n-Decane from their triple points to about $10 \mathrm{Mm} \mathrm{Hg}$, J. Chem. Eng. Data 18, 2, 115-126.

Çengel Y., Boles M. (2001) Thermodynamics: An engineering approach, McGraw-Hill Book Company, Inc., ISBN10:0072549041.

Chang J., Lin C.-C. (2006) A study of storage tank accidents, J. Loss Prev. Process Ind. 19, 51-59.

Chen H.-J., Lin S.-P. (2001) Fire dynamics and solar heating influence on an oval-shaped, Ind. Eng. Chem. Res. 40, 17, 3817-3828.

CSTB (2002) Fire physics for engineers [Physique du feu pour l'ingénieur], CSTB, France, ISBN: 978-2-86891-305-0.

de Hemptinne J.C., Béhar E. (2006) Thermodynamic modelling of petroleum fluids, Oil Gas Sci. Technol. - Rev. IFP Energies nouvelles 61, 3, 303-317.

de Nevers N. (1997) Ambient and solar heating of propane containers, Fire Technol. 33, 3, 230-253.

De Vriendt A.B. (1990) Heat transfer [La transmission de la chaleur]. Vol. 1. Conduction [La conduction], ISBN:2-89105339-7.

Guo X.-Q., Sun C.-Y., Rong S.-X., Chen G.-J., Guo T.-M. (2001) Equation of state analog correlations for the viscosity and thermal conductivity of hydrocarbons and reservoir fluids, J. Petrol. Sci. Eng. 30, 15-27.

Handbook of Chemistry (2004) McGraw-Hill Book Company, Inc., New York, ISBN-10:0071410376

Hauser J., Ciolek W., Fisher H., Forrest H., Grolmes M., Grossel S., Keiter A., Muller A., Nazario F., Nichols F.P., Stipanovich J., Wilday J., Windhorst J. (2001) Vent sizing for fire considerations: external fire duration, jacketed vessels and heat flux variations owing to fuel composition, J. Loss Prev. Process Ind. 14, 403-412.

Ingersoll L.R., Zobel O.J., Ingersoll A.C. (1955) Heat conduction, with engineering, geological, and other applications, 3rd edn., Thames and Hudson, London, pp. xiii, 325.

Karimpour K., Zarghami R., Moosavian M.A., Bahmanyar H. (2016) New fuzzy model for risk assessment based on different types of consequences, Oil Gas Sci. Technol. - Rev. IFP Energies nouvelles $\mathbf{7 1}, 17$.

Khan F.I., Abbasi S.A. (2000) TORAP - a new tool for conducting rapid risk-assessments in petroleum refineries and petrochemical industries, Appl. Energy 65, 87-210.

Kourneta P., Ziomas I., Contini S., Drogaris G. (1994) Development of a model for simulating the variability of the physical properties of substances, stored in various storage tanks, in the presence of an external heat source, J. Hazard. Mater. 39, 1, 1-18.

Lacassagne T., El-Hajem M., Morge F., Simoens S., Champagne J.-Y. (2017) Study of gas liquid mass transfer in a grid stirred tank, Oil Gas Sci. Technol. - Rev. IFP Energies nouvelles 72,7 .

Landucci G., Gubinelli G., Antonioni G., Cozzani V. (2009b) The assessment of the damage probability of storage tanks in domino events triggered by fire, Accident Anal. Prev. 41, 1206-1215.

Landucci G., Molag M., Cozzani V. (2009a) Modeling the performance of coated LPG tanks engulfed in fires, J. Hazard. Mater. 172, 1, 447-456.

Maillet D., André S., Batsale J.C., Degiovanni A., Moyne C. (2000) Thermal quadrupoles, solving the heat equation through integral transforms, Wiley Editor, p. 384, ISBN-10: 0471983209. 
Majer V., Svoboda V. (1985a) Enthalpies of vaporization of organic compounds: a critical review and data compilation, Blackwell Scientific Publications, Oxford, p. 300.

Majer V., Svoboda V. (1985b) Enthalpies of vaporization of organic compounds: a critical review and data compilation, Blackwell Scientific Publications, Oxford, p. 300.

Neau E., Peneloux A., Solimando R., Rogalski M. (1995) Étude d'équations d'état en vue de représenter les propriétés PVT et les équilibres liquide-vapeur d'hydrocarbures, Oil Gas Sci. Technol. - Rev. IFP Energies nouvelles 50, 6, 791-805.

NIST (2012) Data Gateway, http://srdata.nist.gov/gateway/ consulted in 2016.

Nitesh J., Gupta J.P. (2007) Water requirement in tank farm fire, J. Petrol. Sci. Eng. 55, 1-2, 167-173.

Persson B., Lonnermark A., Persson H. (2003) FOAMSPEX: large scale foam application - modelling of foam spread and extinguishment, Fire Technol. 39, 347-362.
Prugh R. (1992) Hazardous fluid releases: prevention and protection by design and operation, J. Loss Prev. Process Ind. 5, 2, 66-72.

Ribaud (1960) Heat conduction in unsteady state [Conduction de la chaleur en régime variable], Gauthier-Villars, ISBN: 155639 60.

Subba R., Gorla R. (2010) Probabilistic analysis of a liquefied natural gas storage tank, Appl. Therm. Eng. 30, 2763-2769.

Wang D., Zhang P., Chen L. (2013) Fuzzy fault tree analysis for fire and explosion of crude oil tanks, J. Loss Prev. Process Ind. 26, 1390-1398.

Williamham C.B., Taylor W.J., Pignocco J.M., Rossini F.D. (1945) Vapor pressures and boiling points of some paraffin, alkylcyclopentane, alkylcyclohexane, and alkylbenzene hydrocarbons, J. Res. Natl. Bur. Stand. (US) 35, 219-244. 